\title{
31 ANOS DO NEDDATE - O resgate da memória "para não apagar o futuro"1
}

\author{
Maria Ciavatta ${ }^{2}$ \\ Gaudêncio Figotto ${ }^{3}$

\section{Apresentação}

Solicitada a coordenar esta sessão comemorativa, inicio a apresentação dos 31 anos do Neddate (Núcleo de Estudos, Documentação e Dados sobre Trabalho e Educação) da Universidade Federal Fluminense, com uma presença que nos é cara, como amigo e como intelectual destacado da área de pesquisa Trabalho e Educação, o Prof. Dr. Gaudêncio Frigotto ${ }^{4}$, para uma conferência sobre a gênese e o desenvolvimento deste núcleo de pesquisa. Professor Titular de Economia Política da Educação desta Universidade, é, atualmente, Professor Adjunto do Programa de Políticas Públicas e Formação Humana (PPFH) da Universidade do Estado do Rio de Janeiro (UERJ), Pesquisador do CNPq, autor de muitos artigos e livros na área, interlocutor de grupos de pesquisa em educação e sociedade no Brasil e no exterior.

O Prof. Gaudêncio dispensa maior apresentação por ter sido professor desta casa, ligado à história da Faculdade de Educação e do Neddate, com o qual participei de sua criação. Participou ativamente no Curso de Graduação em Pedagogia (Niterói e Angra dos Reis), do Programa de Pós-graduação lato sensu, do Curso de especialização em Educação Brasileira e Movimentos

\footnotetext{
${ }^{1}$ Este documento recupera e amplia a participação dos Profs. Drs. Gaudêncio Frigotto e Maria Ciavatta na sessão comemorativa dos 31 anos do Neddate.

${ }^{2}$ Licenciada em Filosofia, Doutora em Ciências Humanas (Educação- PUC-RJ), Professora Titular de Trabalho e Educação da Universidade Federal Fluminense, Ex-coordenadora e atual Docente do Programa de Pós-graduação em Educação desta Universidade, Ex-professora Visitante da Universidade do Estado do Rio de Janeiro, Pesquisadora do CNPq, Coordenadora do Grupo These 'Projetos Integrados de Pesquisas em Trabalho, História, Educação e Saúde (UFF-UERJ-EPSJV-Fiocruz).

3. Licenciado em Filosofia, Doutor em Ciências Humanas (Educação-PUC-SP), Professor Titular de Economia Política da Educação da Universidade Federal Fluminense, ExCoordenadordo Programa de Pós-graduação em Educação desta Universidade, Professor no Programa de Pós Graduação em Políticas Públicas e Formação Humana da Universidade do Estado do Rio de Janeiro, Pesquisador do CNPq, Coordenador do Grupo These 'Projetos Integrados de Pesquisas em Trabalho, História, Educação e Saúde (UFF-UERJ-EPSJVFiocruz).
} 
Sindicais e do Programa de Pós-graduação em Educação, Mestrado e Doutorado.

Meu sentimento é também de agradecimento a Gaudêncio que, de certa forma, expressa os avanços que conseguimos pelas análises que ele sempre fez, na forma de congregar e ajudar a crescer, generosamente, professores e alunos, na vida acadêmica de muitos anos. É importante destacar que a pesquisa, que está no início de nossas atividades comuns neste Núcleo, sempre foi um trabalho coletivo, com o sentimento de confiança e de sinceridade mútuas.

Mas faço esta apresentação, também, com a emoção sofrida deste dia, 12 de maio de 2016, quando o Brasil presencia e se rebela contra um novo momento de autoritarismo, o Golpe parlamentar, midiático e jurídico que estamos vivendo, com o afastamento em curso, da Presidente da República, Dilma Rousseff, eleita com os votos de mais de 54 milhões de brasileiros.

Esta é uma festa de comemoração e de congraçamento, mas compartilho o reconhecimento e a valorização, neste momento grave da vida nacional, da democracia na organização política, na expressão do pensamento, na produção do conhecimento, na condução das ações.

Juntos, nesta oportunidade, recuperamos a memória da conjuntura política e dos fatos que cercam a criação deste núcleo de pesquisas, "para não apagar o futuro". Lutando para manter um incipiente regime democrático, encontrarmos forças para que não se repita a Ditadura Civil-militar (1964-1985) que muitos de nós vivemos. Porque é a memória que permite a projeção do futuro. Não para repeti-lo, mas para entender o presente e projetar o que desejamos ser, corrigir os erros, reconhecer os valores da dignidade humana na vida social e orientar as novas ações. É a memória de tempos passados que se projeta no tempo presente, que permite escrever a história.

O historiador alemão Jorn Rusen ${ }^{5}$, distingue os dois processos de preservação escrita ou oral da vida humana: a memória é o registro da subjetividade social de cada um; a história é a reflexão e o relato, os significados sobre a memória, a explicação dos fatos e suas interpretações. Nosso trabalho, nesta comemoração, não é um trabalho sistemático de história

${ }^{5}$ RUSEN, Jorn. Como dar sentido ao passado: questões relevantes da meta-história. História da Historiografia, n. 2, p. 164-209, março, 2009.

TrabalhoNecessario - www.uff.br/trabalhonecessario; Ano 14, № 25/2016 
do Neddate, mas, sim, um exercício de memória, onde apenas alguns aspectos são destacados sobre as transformações da sociedade, da política e da educação no Brasil, a articulação da docência com a pesquisa, a documentação e as publicações produzidas pelos docentes pertencentes ao Núcleo.

Dedico, especialmente, esta apresentação às colegas Dora Henrique da Costa, Marly Vianna e Zuleide Faria de Melo. Elas e outros familiares e companheiros, entre os quais, José Salles, arriscaram sua juventude e sua vida para salvar, das garras da Ditadura, pessoas e documentos que registram a memória das lutas dos trabalhadores do início do século $X X$, em defesa da regulamentação de seus mais elementares direitos. Essa memória foi preservada no Arquivo de Astrogildo Pereira (jornais operários, panfletos, cartas, fotografias etc.) que hoje constitui o Arquivo Social da Memória Operária Brasileira (ASMOB). ${ }^{6}$ Os depoimentos públicos sobre as ações do salvamento heroico dessa importante documentação foram realizados em diferentes momentos, nos anos 2001, 2007 e 2014, nesta Faculdade de Educação, sob minha coordenação e com o apoio do Neddate, tal como constam do livro Luta e Memória. ${ }^{7}$

Além desta breve introdução, o Prof. Gaudêncio Frigotto apresenta a gênese e o desenvolvimento do Neddate e eu farei uma sucinta exposição sobre a pesquisa no Neddate, seu acervo de documentação e principais publicações. $^{8}$

\section{A gênese e o desenvolvimento do Neddate}

Ao resgatar a memória da gênese e desenvolvimento do NEDDATE ao longo de três décadas cabe, inicialmente, duas pequenas notas, uma de

\footnotetext{
${ }^{6}$ Os originais estão sob a guarda do Centro de Memória e Documentação (CEDEM), da Universidade do Estado de São Paulo (UNESP), na cidade de São Paulo. Há cópias em vários arquivos de documentação sobre a memória dos trabalhadores, entre os quais, o Neddate.

${ }^{7}$ Ciavatta, Maria (coord.), depoimentos de Costa, Dora Henrique da; Dora, Vianna, Marly; Melo, Zuleide Faria de; Luta e memória. O resgate da memória nacional de pessoas e documentos das garras das garras da ditadura. Rio de Janeiro: Revan, 2015.

${ }^{8}$ Agradeço aos Profs. José Luiz Antunes e Lia Tiriba, Coordenadores do Neddate, informações adicionais sobre a produção científica do Núcleo, utilizadas nesta versão revista da fala original.
}

TrabalhoNecessario - www.uff.br/trabalhonecessario; Ano 14, № 25/2016 
ordem metodológica e outra, articulada a esta, referente aos embates políticos na sociedade e na educação em três conjunturas distintas

De Antônio Gramsci retiramos a visão de que uma adequada análise conjuntural implica uma relação cuidadosa do movimento do tempo presente com as ligações no que é a estrutura na sociedade que analisamos. É de Karel Kosik a compreensão de que nesta análise entre o estrutural e o conjuntural devemos averiguar as mudanças nos embates entre as classes e grupos sociais na alteração da realidade e distinguir aquelas mudanças que conservam a estrutura de desigualdade e exploração, daquelas que concorrem para a sua superação. Superação esta, ainda que possa ser parcial, mas que concorre para o horizonte de superação das relações sociais marcadas pela exploração da classe detentora do capital, para uma sociedade socialista.

Ao longo dos trinta e um anos de atividades científicas e de embates políticos mediados pelas primeiras, convivemos com três conjunturas distintas e, agora, uma quarta conjuntura que ao rever este texto para a publicação já estava consumado o golpe de estado empresarial, parlamentar, jurídico, midiático e hoje claramente repressivo policial. Destas três conjunturas duas, mesmo com contradições e limites, foram propositivas no campo social, econômico, cultural e educacional e uma marcada pela resistência ativa ao golpe neoliberal na década de 1990 e que retorna agora com maior poder e violência com o atual golpe de Estado.

Com efeito, em 1985, a ditadura empresarial militar, por suas contradições e pela luta de movimentos sociais, setores sindicais e políticos e instituições científicas encerrava o brutal ciclo de 21 anos. O Neddate surgiu na década de 1980, no contexto dos debates das Conferências Brasileiras de Educação, do esforço de redemocratização do Estado nos estritos limites de nossa cultura política patrimonialista, início dos debates da Constituinte. A IV Conferência Brasileira de Educação, realizada em Goiânia em setembro de 1986, ao seu final publicou a Carta de Goiânia com 21 recomendações para o tema da educação na Constituinte.

Também foi o período de expansão da pós-graduação da área da Educação. Dois programas de pós-graduação em educação tiveram influência direta na concepção e trabalho de pesquisa do Neddate. No plano da concepção teórica e metodológica, o Programa de Pós-Graduação da PUC de 
São Paulo, área de Filosofia, sob a coordenação do professor Dermeval Saviani. Foi nesta área que os estudos sistemáticos do Marxismo, mormente pelo debate das obras de Marx, Engels, Gramsci e Lenin, formou quadros que se apropriaram da concepção marxista de realidade social e do método dialético materialista histórico de conhecimento materialista. Também o pensamento crítico marxista na área de educação tinha uma referência em Leandro Konder, professor do Departamento de História da UFF, depois do Departamento de Educação da PUC-RJ, pesquisador que orientou a tese de doutorado de Maria Ciavatta.

No plano da concepção do trabalho de organização, debate e orientação coletiva na pesquisa, a influência vem de dupla experiência. Do programa da PUC/SP e do Instituto de Estudos Avançados em Educação (IESAE) da Fundação Getúlio Vargas/RJ. Aqui a professora Maria Ciavatta, principal idealizadora do NEDDATE, no início, Programa de Pesquisas em Trabalho e Educação, e eu que chegava na Universidade Federal Fluminense como professor Visitante, pudemos nos confrontar com a escola empirista positivista de pesquisa no Programa ECIEL (Estudios Conjuntos de Integración Económica em Latinoamérica), sob a coordenação de Cláudio de Moura Castro. Para ambos foi uma experiência de constante embate de referências e neste sentido um ganho para poder perceber na teoria e empreender na prática um trabalho empirista e positivista rigoroso. Também, a despeito de visões de mundo e de conhecimento, diametralmente opostas ou mesmo antagônicas, reconhecemos que Castro não tolhia o debate, ao contrário estimulava a polêmica.

Daquele período, até o presente, o NEDDATE teve presença ativa na Associação de Pesquisa e Pós-Graduação em Educação (ANPED) e na criação do GT Trabalho e Educação, sendo que em diferentes momentos o mesmo foi coordenado por membros do NEDDATE. ${ }^{9}$ Foi uma conjuntura curta, mas que colimou com a Constituição de 1988, debates acalorados na primeira eleição direta à Presidência da República e o encaminhamento dos debates na nova LDB (Lei de Diretrizes e Bases da Educação) e no Plano Nacional de Educação.

9. Dos anos 1980 aos anos 2010, em diversas gestões, Gaudêncio Frigotto, Maria Ciavatta, Eunice Trein, Sonia Maria Rummert.

TrabalhoNecessario - www.uff.br/trabalhonecessario; Ano 14, № 25/2016 
A eleição de Collor de Mello demarca uma nova conjuntura, esta de retrocesso e de esfacelamento dos avanços conquistados na Constituição. A conjuntura que vai de 1990 a 2003, em especial os oito anos do governo Fernando Henrique Cardoso, marcam a introdução na economia e na educação do ideário neoliberal. Uma década de venda fraudulenta do patrimônio público, de longo postergar da LDB produzida no debate democrático e com o desfecho de um substitutivo do Senador Darcy Ribeiro que deu, como lembrou Florestan Fernandes, ao governo o texto que the interessava. Uma LDB minimalista, como a definiu Dermeval Saviani, e que apenas assegurava o que já tinha sido feito por decretos e portarias.

O NEDDATE participou ativamente da resistência ativa na produção acadêmica e nos grandes debates nacionais com destaque nos CONEDs. Internamente, no programa de Pós-graduação em Educação da UFF, a introdução das disciplinas Teoria e Educação I e Teoria e Educação II teve grande participação de membros do NEDDATE, assim como na concepção das disciplinas "Economia da Educação" e de "Trabalho e Educação", estas últimas também na graduação.

Foi nesta década, paradoxalmente que coletivamente aprofundamos o entendimento coletivo, tanto dos pressupostos fundamentais da concepção materialista histórica da realidade, quanto do método materialista dialético de apreendê-la. Os pressupostos que foram se consolidando são:

a) Qualquer que seja o método de conhecimento, o mesmo tem de forma explicita ou implícita, uma determinada concepção de natureza humana e de sociedade e de acordo com esta concepção o sentido de sua ação prática ou de sua práxis. Portanto, a dimensão ontológica do ser social antecede e define a natureza das concepções epistemológicas e da orientação da ação política ou da práxis.

Deste primeiro pressuposto deriva o que Karel Kosik (1986) denominou de monismo materialista em contraposição ao pluralismo metodológico na compreensão da realidade socio-histórica.

O monismo materialista, que concebe a realidade como complexo construído e formado pela estrutura econômica, e, portanto, por um conjunto de relações sociais que os homens estabelecem na produção e no relacionamento com os meios de produção, pode constituir a base de uma coerente teoria 
das classes e ser o critério objetivo para a distinção entre mutações estruturais - que modificam o caráter da ordem social -e mutações derivadas, secundárias, que modificam a ordem social, sem, porém, mudar essencialmente seu caráter (KOSIK, 1976, p.105) $)^{10}$

É este autor amplamente utilizado nos curos de formação e nos debates por membros do NEDDATE que nos dá uma síntese da visão materialista do ser social e a encontramos em Karel Kosik quando indica que na produção e reprodução de si mesmo os seres humanos produzem:

a) os bens materiais, o mundo materialmente sensivel, cujo fundamento é o trabalho;

b) as relações e as instituições, o complexo das condições sociais;

c) e sobre a base disto, as ideias, as concepções, as emoções, as qualidades humanas e os sentidos correspondentes.

Sem o sujeito, estes produtos sociais do homem ficam privados de sentido, quanto o sujeito sem os pressupostos materiais é uma miragem vazia. A essência do homem é a unidade de objetividade e subjetividade. (KOSIK, op. cit. p.113).

b) O segundo pressuposto, derivado deste primeiro, é de que nas sociedades de classe as teorias e métodos de análise não se somam, mas são disputas sobre a compreensão de como a realidade humana, em todas as suas dimensões, é socialmente produzida. Isto não elide 0 fato de que determinadas descobertas feitas por outros referenciais não possam ser incorporadas de forma subordinada. Marx foi um exemplo em relação à filosofia alemã, empirismo inglês e socialismo utópico francês.

c) Por fim, um terceiro pressuposto, é de que, como sublinha Fredric Jameson (1994) $)^{11}$, o materialismo histórico dialético não é o único referencial teórico e metodológico que faz a crítica ao capitalismo, mas o único que tem como objeto o sistema capitalista e busca desvelar, pela raiz, seu metabolismo social na perspectiva, da sua superação. Um método que postula que suas descobertas não parem na descoberta, mas atuem praticamente no seio das relações sociais capitalistas na busca de sua superação.

\footnotetext{
${ }^{10}$ Kosik, Karela. A dialética do concreto. Rio de Janeiro: Paz e Terra, 1976.

11 Jameson, Fredric. Espaço e imagem. Teorias do pós-moderno e outros ensaios. Rio de Janeiro. Editora das UERJ, 1994.
}

TrabalhoNecessario - www.uff.br/trabalhonecessario; Ano 14, № 25/2016 
Não só a produção, nesta conjuntura, dos membros do NEDDATE, incluindo docentes pesquisadores, doutorandos, mestrandos e graduandos, mas a organização do I Intercrítica com nove Grupos Trabalho e Educação revelaram tanto o aprofundamento da compreensão dos pressupostos acima no trabalho prático de produção do conhecimento, quanto o necessário engajamento na luta política na sociedade e na educação.

Foi na resistência ativa nesta conjuntura que se formou uma ampla e diversa base social para a eleição à Presidência da República de um exoperário, Luiz Inácio Lula da Silva. Uma base social que tinha como expectativa um governo que assumisse reformas estruturais apoiado nesta mesma base. Os balanços críticos são diversos e nem sempre concordantes no pensamento crítico, inclusive no interior do NEDDATE. Não cabe aqui retomá-los. O grupo THESE ${ }^{12}$, podemos dizer, cuja origem é o NEDDATE, que hoje reúne pesquisadores do mesmo, vinculados ou não ao Programa de Pós-Graduação em Educação da UFF, do Programa de Pós-graduação em Políticas Públicas e Formação Humana (PPFH) do Programa de Pós-Graduação em Educação Profissional em Saúde, tem feito este balanço.

Podemos assumir que a visão dominante é de que, nos dois mandatos de Lula da Silva e um mandado de Dilma Rousseff, o diferencial em relação ao governo de Fernando Henrique Cardoso foi a retomado da ideia e incentivo ao desenvolvimento; a criação de 18 novas Universidades públicas, demanda de regiões e de movimentos sociais; a criação de centenas de Institutos Federais de Educação, Ciência e Tecnologia; política de distribuição de renda via ganhos reais do salário mínimo e amplas políticas de transferência de renda através de programas sociais; uma política externa de fortalecimento da unidade latino-americana e de não alinhamento automático com o império Norte-americano; e a participação ativa na criação do grupo BRICS (Brasil, Rússia, Índia, China e África do Sul) que redefiniu a geopolítica mundial.

Mas é fundamental dizer que isto tudo não se deu mediante a definição de um projeto de sociedade e de educação que rompesse com as estruturas dominantes de poder econômico, político, jurídico e midiático, tendo como sustentação a base que os elegeu- O bloco dominante do PT (Partido dos

\footnotetext{
${ }^{12}$ Grupo de Projetos Integrados de Pesquisas em Trabalho, História, Educação e Saúde (UFFUERJ-EPSJV-Fiocruz).
}

TrabalhoNecessario - www.uff.br/trabalhonecessario; Ano 14, № 25/2016 
Trabalhadores) e do governo optou por um projeto de poder com um pacto com as forças que sempre resistiram e, quando ameaçadas, não se pejam, como sublinha o escritor Luiz Fernando Verissimo, em deflagrar golpes de Estado: "Está no DNA da classe dominante brasileira, que historicamente derruba pelas armas se for preciso, toda ameaça ao seu domínio, seja qual for sua sigla" ${ }^{13}$.

A falta de um projeto de sociedade e de educação permitiu que o inimigo se organizasse dentro do aparelho do Estado com a anuência do governo. Enquanto a economia crescia, com o PIB chegando a mais de $7 \%$ ao ano, o aumento real do salário mínimo, as diferentes políticas de transferência de renda às frações mais pobres da classe trabalhadora, a expansão de universidades públicas e Institutos Federais de Educação, Ciência e Tecnologia com inclusão de índios, quilombolas etc., não incomodavam. Com a mais grave crise do sistema capital em nível planetário em 2008 e seus reflexos no Brasil, com PIB negativo e vendo que, para manter as políticas públicas em curso, o risco era de perdas em seus ganhos, construiu-se a opinião púbica para um novo golpe de Estado.

O fato novo é que a unidade orgânica da classe dominante brasileira, no seu pluralismo de interesses, pode fazer o golpe sem o apelar para as forças armadas, mas agora com o papel ativo da mídia empresarial, do parlamento, de parte do judiciário, mormente do Ministério Público, e a presença ativa da Polícia Federal. Nova é, também, a estratégia de criminalizar antes de qualquer julgamento dentro dos trâmites do Estado de direito. Para tanto, usa-se a deleção premiada de empresários e políticos presos que, a partir de seus depoimentos, muitos apenas parciais ou de acordo com determinados interesses, filtra-se o que interessa e alardeia-se em espetáculos midiáticos e com as expressões de organização criminosa, quadrilha etc. e, por outro porte, uma autonomia nunca vista à Polícia Federal e ao Ministério Público Federal ${ }^{14}$.

\footnotetext{
${ }^{13}$ Ver a crônica de Luiz Fernando Verissimo. Ódio, O Globo, caderno de Opinião de 25/06/2015. Retirado de http://oglobo.globo.com/opiniao/odio-165465330, em 14 de novembro de 2016.

${ }^{14}$ Para uma maior compreensão do sentido grave desta novidade no âmbito jurídico e policial, ver a análise de Giorgio Agamben (2015) sobre o papel soberano da polícia e a natureza da delação premiada mediante a categoria religiosa do arrependimento. Em relação ao papel da polícia ver texto de Antônio Cândido sobre O caráter da repressão, publicado em 1972 pelo Jornal Opinião e recuperado pelo portal Outras Palavras em 8 setembro de 2016.
} 
Somos interpelados a um duplo desafio: de, à luz do materialismo histórico, apreender a especificidade e virulência e, ao mesmo tempo não ficar apenas na batalha das ideias, mas ampliar todas as formas possíveis a resistência ativa no plano da ação política. Trata-se, uma vez mais, de uma luta para renascer das cinzas.

\section{Pesquisa em Trabalho e Educação no Neddate}

Agradeço, em nome do Neddate, ao Prof. Gaudêncio, sua presença e valiosa contribuição nesta comemoração.

Minha fala aqui tem a ver com a pesquisa, porque foi a pesquisa que deu origem a este Núcleo e ao grupo que foi se formando em diferentes momentos, ao longo de mais de três décadas (1985-2016). Sempre temos a visão do presente, mas o presente tem um passado de um coletivo de muitas pessoas que foram contribuindo ao longo do tempo.

O campo Trabalho e Educação, como área teórico-empírica de pesquisas e como escola de pensamento, através da pesquisa, do ensino e da extensão nesta Faculdade, no Neddate, estuda os diversos aspectos da vida social: a relação capital e trabalho, suas consequências para a vida das populações, em nível nacional e internacional; a educação e a organização dos trabalhadores em sindicatos, em escolas sindicais e nos movimentos sociais; 0 ensino médio, a educação de jovens e adultos, a educação profissional, técnica e tecnológica; a produção associada e a cultura do trabalho; a pesquisa histórica do trabalho e da educação, as fontes alternativas do mundo do trabalho e da educação, como a história oral e a fotografia. Além das questões teóricas que dão sustentação ao campo Trabalho e Educação, as questões foram emergindo das políticas educacionais levadas adiante pelo Estado, através do Ministério da Educação (MEC), das Secretarias Estaduais de Educação (SEEs), dos organismos internacionais, das reivindicações dos diversos grupos, classes e setores da sociedade brasileira e latino-americana.

Através da pesquisa e da orientação de jovens estudantes da pósgraduação e da graduação, no início da redemocratização do país, em 1985, começamos a trabalhar juntos, Gaudêncio e eu, em projetos de pesquisa e de orientação coletiva de dissertações de mestrado. Esta história singela nos seus 
objetivos iniciais, adquiriu, ao longo do tempo, maior complexidade e relevância, com nossa participação com colegas de outras universidades na criação e crescimento do "Grupo Trabalho e Educação" da Associação de Pósgraduação e Pesquisa em Educação (ANPEd).

Em 1985, quando começamos o trabalho conjunto que viria se tornar o Neddate, denominávamos, apenas, Programa de Pesquisas em Trabalho e Educação. A Faculdade de Educação funcionava ainda no prédio antigo, na Rua Dr. Celestino, onde tudo era muito apertado. A partir do início dos anos 1990, a mudança para o Campus do Gragoatá foi a glória com o amplo espaço do novo prédio e do campus, um lugar muito bonito e agradável. Ao logo dos anos 1990 e 2000, foi expressiva a afirmação do Neddate com a entrada de novos professores e de mais alunos para o Campo de Confluência Trabalho e Educação (hoje Linha de Pesquisa Trabalho e Educação) e com a criação do Curso de Doutorado em Educação em 1994/95.

Foi a pesquisa que motivou e deu coesão a nosso grupo inicial em 1985. Pautamos a organização do Núcleo com base na teoria, na empiria e na documentação da pesquisa dos professores e na preservação de fontes primárias e secundárias - daí incluirmos "documentação e dados" no nome do Neddate. Também foi importante para a afirmação do Núcleo, o trabalho coletivo de coordenação do Núcleo.

Dos primeiros anos de 1990 até o início dos anos 2000, a Sala 525 do Bloco D, que conquistamos na mudança da Faculdade de Educação para o Campus do Gragoatá, era muito frequentada por nossos bolsistas e orientandos. Em uma época em que ainda não dispúnhamos de acervos digitais de documentos, nem do Banco de Teses da CAPES. O acervo de dissertações e teses de Trabalho e Educação, impressas, da UFF e de outras universidades, de cujas bancas de defesa, nós, professores participávamos, era um espaço aberto aos alunos e bolsistas para o desenvolvimento de seus trabalhos acadêmicos.

Não obstante o peso intelectual do Neddate na pesquisa nacional, os equipamentos (mesas, cadeiras, armários, computadores) eram mínimos, até que, com apoio da Reitoria e da Faculdade, a habilidade de alguns coordenadores e recursos de projetos de apoio à pesquisa, a sala conquistou bons móveis, computadores, impressoras, obtidos, especialmente, por Sonia 
Rummert, José Rodrigues, Ronaldo Rosas no início dos anos 2000; Gaudêncio Frigotto, Eveline Algebaile, Maria Ciavatta, Lia Tiriba, pelo Grupo These / Projeto Faperj, nos anos 2012. O cuidado de José Luiz Antunes e Lia Tiriba com o ambiente do Neddate e com o acervo de documentação, os pôsteres e cartazes expostos nas paredes e nos armários, lembram a história acadêmicocientífica do Núcleo.

Do ponto de vista teórico, partimos da crítica ao positivismo, aos estudos funcionalistas de base estatística, para as análises políticas da sociedade e da educação. "Diferente do campo da história, da sociologia e, em um sentido dominantemente economicista, da economia, as pesquisas sobre Trabalho e Educação e sua relação com as práticas educativas, eram bastante recentes"15nos anos 1980 e 1990.

A crítica marxista, que pôde ser feita após o fim do regime ditatorial, nos anos 1980, ensina que o mundo é relacionado, e que a escola não existe sozinha. Não existe o professor, o aluno, a escola, separadamente. Existem o professor, o aluno, a escola, os cursos, os currículos, em relação uns com os outros, em um certo espaço-tempo. O mundo não é uma simples quantidade de aspectos; os aspectos ganham sentido e significado a partir das relações que se estabelecem entre eles. Ontologicamente, a sociedade começou a existir e a escola e a sociedade começaram a se educar em situação de reciprocidade.

De início, esta área de pesquisa, na ANPED, como Grupo de Trabalho, autodenominava-se Educação e Trabalho. Foi o estudo de Marx, do materialismo histórico, e a compreensão da educação como parte da sociedade e de suas práticas sociais, valores, ideologias etc., a história como produção social da existência, que levaram à inversão da relação, dando centralidade ao trabalho, e o Grupo passou a chamar-se Trabalho e Educação.

Esta mudança tem muito a ver com a forma como se constituem outros objetos, fenômenos, sujeitos sociais. Esta é uma questão muito importante porque nos dá força de argumentação. Nossos temas estão cheios de laços, de relações - o que é uma dificuldade para a pesquisa, não é uma facilidade. Mas são importantes porque são eles que constituem a totalidade social e as

${ }^{15}$ NÚCLEO de Estudos, Documentação e Dados sobre Trabalho e Educação (NEDDATE). Niterói / Rio de Janeiro: UFF-NEDDATE, 19 de setembro de 1996, impresso, p. 3.

TrabalhoNecessario - www.uff.br/trabalhonecessario; Ano 14, № 25/2016 
mediações que permitem reconstruir, historicamente, nossos objetos de pesquisa.

Nesta forma de ver, a sociedade que estudamos e onde vivemos não é uma sociedade qualquer, é uma sociedade com características próprias, uma sociedade capitalista. Os sujeitos sociais estabelecem relações múltiplas em seus espaços-tempos para a produção da vida, com desdobramentos na cultura, na educação, na ética, na política. Mas não é um conhecimento teórico, acabado, é também a exigência da práxis, da ação política que dá sentido à vida e ao trabalho;

A pesquisa no Neddate - A crítica marxista da produção do conhecimento começa com a crítica da economia política que é o aspecto decisivo da sociedade na relação entre o trabalho e a educação e os sistemas de ensino. Esta análise crítica se completa com a concepção de história que, na obra de Marx, não aparece sistematizada como a análise do capital, mas se expressa em todos seus escritos. Estes são apoiados em farta documentação, localizados no espaço e no tempo dos acontecimentos analisados e na concepção clara de história, presente na Ideologia Alemã. ${ }^{16}$ É a concepção da história como produção social da existência, segundo a qual, os seres humanos precisam comer, vestir-se, precisam se abrigar para fazer história.

Esta concepção foi uma revolução não reconhecida ou não admitida por todos os historiadores. Para mim foi o maior descobrimento na pesquisa social, em trabalho e educação. Foi o início de minha pesquisa neste Núcleo. Foi a pesquisa histórica, que comecei antes de vir para esta Universidade, mas que aprofundei aqui, que me deu uma consciência diferente daquilo que estudei quando era mais jovem.

A história não é apenas um conjunto de fatos, de grandes nomes, das ações de homens ilustres (reis, duques, generais). A história é a vida de todos nós. Se vai para os livros ou não, depende de sua importância para o coletivo, e do poder de quem seleciona os fatos para a escrita da história. Mas a história é também a nossa história, daquilo que somos, nossa história profissional, a história de nossa família, da cidade de origem, da região. É esta visão de

\footnotetext{
${ }^{16}$ Marx Engels. A ideologia alemã (Feuerbach). 11ª . ed. São Paulo: Hucitec, 1999.

TrabalhoNecessario - www.uff.br/trabalhonecessario; Ano 14, № 25/2016
} 
história que não é reconhecida por muitos historiadores, e da qual nem mesmo os estudiosos do marxismo se dão conta.

Além de Marx, foram importantes, para o aprofundamento estudos de história que desenvolvi no Programa de Pós-graduação e no Neddate, Adam Schaff, Hobsbawn, Thompson, Ciro Flamarion Cardoso, Fernand Braudel, Benjamin. Foi o entendimento de que os trabalhadores não apenas trabalham, eles vivem em sociedade, têm grupos de pertencimento, clubes, igrejas, coligações políticas. Admitir os trabalhadores com essas características não desmerece seu estudo como força de trabalho, antes amplia a sua concepção como classe social. Como diz a música dos Titãs: "A gente não quer só comida, a gente quer comida, diversão e arte". Mesmo os trabalhadores mais subalternos na divisão social do trabalho, precisam de arte, de beleza, de afeto, de conhecimento.

Mas a investigação social não é uma atividade etérea, precisa de espaço, precisa de um mínimo de livros, de organização. No encaminhamento das discussões teóricas no coletivo e na organização do espaço, atuaram as várias duplas de coordenadores e vice-coordenadores do Neddate: Gaudêncio Frigotto, Maria Ciavatta, Eunice Trein, Sonia Maria Rummert, José Rodrigues, Ronaldo Rosas, Angela Siqueira, Lia Tiriba, José Luiz Antunes, Jaqueline Ventura, Francisco José Silveira Lobo, Maria Inês Bonfim, Rosilda Benácchio, além da presença e apoio dos professores, Dora Henrique da Costa, Lea Calvão, Luciana Requião, Sandra Moraes, Zuleide da Silveira, Cláudio Fernandes e nossos bolsistas, mestrandos e doutorandos. ${ }^{17}$

O Neddate é um grupo institucional da Faculdade de Educação, coordenado, neste ano, por José Luiz Antunes e Lia Tiriba. Como tal, abriga outros grupos de pesquisa: "Trabalho e Educação - Neddate" sob a coordenação da Profa. Lia Tiriba e Jaqueline Pereira Ventura; o "Grupo THESE - Projetos Integrados de Pesquisas em Trabalho, História, Educação e Saúde (UFF-UERJ-EPSJV-Fiocruz)" sob a coordenação dos Profs. Maria Ciavatta, Gaudêncio Frigotto, Marise Ramos, Eveline Algebaile e Júlio César França

\footnotetext{
${ }^{17}$ Os nomes das dezenas de estudantes que colaboraram com o Neddate e se formaram como graduandos e pós-graduandos, estão citados nos Boletins do Neddate e, mais recentemente, nos registros elaborados por Lia Tiriba e José Luiz Antunes. V. site do Neddate:http:/neddate.uff.br/
} 
Lima; "Educação de Jovens e Adultos Trabalhadores (EJATRAB)", sob a coordenação da Profa. Sonia Maria Rummert e Jaqueline Pereira Ventura.

Importantes, também, ao longo dos anos, desde sua criação, nos anos 1980, foram os intercâmbios com grupos de pesquisa, entre os quais, o "GT Trabalho e Educação" da ANPEd, o "Núcleo de Estudos Trabalho e Educação (NETE-UFMG)", o "Grupo de Estudos e Pesquisas Sobre Trabalho e Educação (GEPTE - UFPa)", o "Grupo de Estudos e Pesquisas em Trabalho, Educação e Tecnologia" (GETET-UFTPr); e outras instituições internacionais, tais como o "Programa Alternativas Pedagógicas na América Latina" (APPEAL, Universidade de Buenos Aires - Argentina), "Asociación de Educadores de Latinoamérica y el Caribe" (Cuba, Argentina, Peru, Venezuela, Colômbia), "Consejo Latinoamericano de Ciencias Sociales (CLACSO)"; Universidad Pedagógica Nacional (México), Universidade de Lisboa (Portugal)

Acervo de documentação - Na teoria, na empiria e na documentação de fontes primárias e secundárias, a preservação das fontes sempre foi objeto de muita dificuldade na sistematização e continuidade dos trabalhos empreendidos. Nunca tivemos um funcionário técnico para manutenção do espaço do Neddate e para o trabalho específico de arquivo e documentação.

No acervo de relatórios e fontes primárias ou secundárias de difícil acesso, consta a documentação de projetos concluídos dos pesquisadores do Núcleo e seus bolsistas, orientandos, mestrandos e doutorandos. O acervo conta também com os livros publicados pelos professores do Núcleo, textos clássicos básicos para o estudo da relação trabalho e educação. Continua hoje, em lento processo de organização por bolsistas com a supervisão de professores. Alguns documentos internos que registram a relação dos projetos e a produção científica dos professores podem ser acessados em Núcleo (op.cit., 1996) 18 e nos documentos (TIRIBA,; BENÁCCHIO, 2011; PORTIFÓLIO, 2011; PRODUÇÃO, 2011; CIAVATTA et al., 2016) ${ }^{19}$ que constam do site do Neddate http://www.neddate.uff.br/

\footnotetext{
${ }^{18}$ Op. cit., p. 5-6.

19 Tiriba, Lia; Benácchio, Rosilda. NEDDATE e seus trabalhos necessários. TrabalhoNecessário, ano 9, n. 13, Número especial, 2011; Portifólio - NEDDATE, 2011; Produção científica dos pesquisadores do NEDDATE, 2011; Ciavatta, Maria et al. Projetos de pesquisa dos professores do NEDDATE, 1984-2016.
}

TrabalhoNecessario - www.uff.br/trabalhonecessario; Ano 14, № 25/2016 
Publicações - As publicações foram sempre uma contribuição substantiva para a imagem e reconhecimento acadêmico-científico do Neddate na área Trabalho e Educação. De forma não exaustiva, recuperamos aqui, publicações periódicas do Núcleo e livros coletivos e individuais elaborados a partir das pesquisas realizadas.

A primeira publicação periódica foi o Boletim do Neddate, impresso artesanalmente, com a coordenação de diferentes professores do Núcleo, nos anos 1990 e início de 2000. Neles estão presentes os temas mais expressivos em termos de políticas educacionais, do inovador Curso de Pedagogia de Angra dos Reis e de discussões teórico-metodológicas da pesquisa.

A Série Estudos Neddate, pretendia ser uma divulgação interna de aspectos de pesquisas em andamento. Teve poucos números e pouca adesão dos pesquisadores do Neddate, mas registrou etapas da pesquisa sobre imagens fotográficas de Maria Ciavatta e os depoimentos públicos das protagonistas do salvamento do Arquivo Astrogildo Pereira no tempo Ditadura.

Um passo importante foi a revista eletrônica "TrabalhoNecessário;" publicada a partir dos anos 2000, sob a direção de Ronaldo Rosas por cerca de uma década e, a seguir, por Sonia Maria Rummert e Jaqueline Ventura. A revista foi criada on line, com qualidade e recursos para abrigar um número grande de artigos, resenhas etc.. Fez parte da política de publicação e socialização ampliada do Núcleo. Os Boletins são transformados em Informativos Neddate, de curta duração. A Revista foi a concretização da ideia que vinha há muito tempo sendo gerada.

Os artigos ${ }^{20}$ e livros são, talvez, o legado mais importante do Núcleo para a área Trabalho e Educação, pela riqueza de pesquisa e de divulgação, por diferentes periódicos e editoras nacionais e estrangeiros. Podendo omitir alguns títulos e autores por não ter podido realizar uma pesquisa sistemática, citamos os seguintes:

- A produtividade da escola improdutiva (1984), de Gaudêncio Frigotto;

- O ensino de $2^{\circ}$. Grau: Trabalho e Educação em Debate(1988), de Maria Aparecida Ciavatta Franco e Maria Laura B. Franco (orgs.);

- Estudos comparados de educação na América Latina (1992), de Maria Ciavatta (org.);

${ }^{20} \mathrm{~V}$. a extensa lista de artigos em "Produção científica dos pesquisadores do NEDDATE", 2011,http://www.neddate.uff.br/

TrabalhoNecessario - www.uff.br/trabalhonecessario; Ano 14, № 25/2016 
- Educação e crise do capitalismo real (1995), de Gaudêncio Frigotto;

- Educação e Identidade dos trabalhadores. As concepções do capital e do trabalho (2000), de Sonia Maria Rummert;

- A experiência do trabalho e a educação básica (2000), de Gaudêncio Frigotto e Maria Ciavatta (orgs.) - primeiro livro coletivo do Neddate;

- Economia popular e cultura do trabalho - Pedagogia(s) da produção associada (2001), de Lia Tiriba;

- Teoria e Educação no labirinto do capital (2001), de Gaudêncio Frigotto e Maria Ciavatta (orgs.);

- O mundo do trabalho em imagens. A fotografia como fonte histórica (Rio de Janeiro, 1900-1930), (2002), de Maria Ciavatta;

- Trabalho e Educação. Arquitetos, abelhas e outros tecelões da economia popular e solidária (2004), de Iracy Picanço e Lia Tiriba (orgs.)

- A leitura de imagens na pesquisa social (2004), de Maria Ciavatta e Nilda Alves (orgs.);

- Ensino Médio Integrado. Concepção e contradições (2005), de Gaudêncio Frigotto, Maria Ciavatta e Marise Ramos (orgs.);

- A formação do cidadão produtivo. A cultura de mercado no ensino médio técnico (2006), de Gaudêncio Frigotto, Maria Ciavatta (orgs.);

- O Músico-Professor de Luciana Requião, 2006;

- O Pensamento Pedagógico Empresarial no Brasil, de José dos Santos Rodrigues(2006-2007)

- Memória e temporalidades do trabalho e da educação (2007), de Maria Ciavatta (coord.);

- Políticas de formação de jovens e adultos no Brasil e em Portugal (2009), de Sonia Maria Rummert e Gaudêncio Frigotto (orgs.);

- Mediações históricas de trabalho e educação. Gênese e disputas na formação dos trabalhadores (Rio de Janeiro, 1930-1960), (2009), de Maria Ciavatta;

- A pesquisa histórica em Trabalho e Educação (2010), de Maria Ciavatta e Ronaldo Rosas Reis (orgs.);

- Celso Suckow da Fonseca (2010), de Maria Ciavatta e Zuleide Simas da Silveira;

- Contradições entre capital e trabalho: concepções de educação tecnológica na reforma do ensino médio e técnico, de Zuleide Simas da Silveira, 2010

- Trabalho e Educação de jovens e adultos (2011), de Lia Tiriba e Maria Ciavatta (orgs.);

- Gaudêncio Frigotto. Um intelectual crítico nos pequenos e nos grandes embates (2012), de Maria Ciavatta (org.);

- O trabalho docente e os caminhos do conhecimento (2015), de Maria Ciavatta;

- Luta e Memória. A preservação da memória histórica do Brasil e o resgate de pessoas e documentos das garras de Ditadura (2015), de Dora Henrique da Costa, Marly Vianna, Zuleide Faria de Melo e Maria Ciavatta (coord.);

- Trabalho e Educação. Análises críticas sobre a escola básica (2015), de Jaqueline Ventura e Sonia Maria Rummert (orgs.), o segundo livro coletivo do Neddate.

TrabalhoNecessario - www.uff.br/trabalhonecessario; Ano 14, № 25/2016 
Finalizando, para além da memória, história, documentações e publicações do Núcleo, que procuramos resgatar, mais recentemente, cabe destacar a forma como o Neddate vem se organizando e sendo gerido, sempre com base no trabalho coletivo. A criação de uma Coordenação Colegiada foi um dos passos que permite ao Núcleo dar materialidade às diferentes políticas em seu meio, através das diversas Linhas de Ação.

Temos muitos motivos para comemorar estes 31 anos. Vamos ao debate e aos livros que estão sendo lançados hoje ... ${ }^{21}$

Niterói, 12 de maio de 2016

\footnotetext{
${ }^{21}$ Ventura; Jaqueline; Rummert, Sonia Maria. Trabalho e Educação. Análises críticas sobre a escola básica. Campinas: Mercado das Letras, 2015; Ciavatta, Maria. O trabalho docente e os caminhos do conhecimento - A historicidade da educação profissional. Rio de Janeiro: Lamparina, 2015; Ciavatta, Maria (coord.), depoimentos de Dora Henrique da Costa; Marly Vianna; Zuleide Faria de Melo. Luta e memória. A preservação da memória histórica do Brasil e o resgate de pessoas e documentos das garras de Ditadura. Rio de Janeiro: Revan, 2015.
} 